\title{
How can monoclonal antibodies be harnessed against neglected tropical diseases and
} other infectious diseases?

\section{Laustsen, Andreas Hougaard}

Published in:

Expert Opinion on Drug Discovery

Link to article, DOI:

10.1080/17460441.2019.1646723

Publication date:

2019

Document Version

Peer reviewed version

Link back to DTU Orbit

Citation $(A P A)$ :

Laustsen, A. H. (2019). How can monoclonal antibodies be harnessed against neglected tropical diseases and other infectious diseases? Expert Opinion on Drug Discovery, 14(11), 1103-1112.

https://doi.org/10.1080/17460441.2019.1646723

\section{General rights}

Copyright and moral rights for the publications made accessible in the public portal are retained by the authors and/or other copyright owners and it is a condition of accessing publications that users recognise and abide by the legal requirements associated with these rights.

- Users may download and print one copy of any publication from the public portal for the purpose of private study or research.

- You may not further distribute the material or use it for any profit-making activity or commercial gain

- You may freely distribute the URL identifying the publication in the public portal 
Address for correspondence: 
1. Therapies based on monoclonal antibodies against bacterial and viral agents have already entered the clinic, while no monoclonal antibodies against parasites, animal envenoming, or mushroom poisonings have been tested in the clinical setting

2. Neglected tropical diseases represent a golden opportunity for antibody developers, as there are many scientifically low-hanging fruits in this field

3. An increasing number of therapeutic monoclonal antibody discoveries has been reported for neglected tropical diseases and other infectious diseases

4. Monoclonal antibodies may be particularly useful for developing therapies against intoxications caused by both animals and bacteria

5. Low cost of manufacture and selective cross-reactivity are key challenges for developing monoclonal antibodies against neglected tropical diseases and other infectious diseases

6. Treatment against snakebite envenoming and bacterial and viral infections will likely require the use of oligoclonal antibodies for multi-target neutralization 


\section{Abstract}

387 Introduction: Monoclonal antibody-based therapies now represent the single-largest class of molecules undergoing clinical investigation. Although a handful of different monoclonal antibodies have been clinically approved for bacterial and viral indications, as well as rabies, therapies based on monoclonal antibodies are yet to fully enter the fields of neglected tropical diseases and other infectious diseases.

Areas covered: This review presents current state-of-the-art in the development and use of monoclonal antibodies against neglected tropical diseases and other infectious diseases, including viral, bacterial, and parasitic infections, as well as envenomings by animal bites and stings. Additionally, a short section on mushroom poisonings is included. Key challenges for developing antibody-based therapeutics is discussed for each of these fields.

397 Expert opinion: Neglected tropical diseases and other infectious diseases represent a golden 398 opportunity for academics and technology developers for advancing our scientific capabilities within 399 the understanding and design of antibody cross-reactivity, use of oligoclonal antibody mixtures for 400 multi-target neutralization, novel immunization methodologies, targeting of evasive pathogens, and 401 development of fundamentally novel therapeutic mechanisms of action. Furthermore, a huge 402 humanitarian and societal impact is to gain by exploiting antibody technologies for the development 403 of biotherapies against diseases, for which current treatment options are suboptimal or non-existent. 


\section{Introduction}

For millions of years, viruses, bacteria, parasites, and natural toxins have represented a daily threat and disease burden for humankind. Although many diseases caused by these pathogens are now under control, particularly due to improved hygiene, effective vaccination programs, and the development of antibiotics, many diseases remain untreatable or have reemerged as a result of development of resistance towards therapy $[1,2]$. Some of these diseases are infectious diseases, whereas others are non-communicable. A special cross-category of diseases are the "neglected tropical diseases", which are tropical diseases (most of them infectious) that mostly affect impoverished communities having little political voice, and thus perpetuate poverty and vulnerability. In general, these diseases have received little attention from health authorities, research agendas, and the pharmaceutical industry. The World Health Organization currently lists 20 diseases as category A neglected tropical diseases that are of the highest importance. These include viral, bacterial, parasitic diseases, and snakebite envenoming (Table 1) [3]. These and other infectious diseases are caused by foreign agents, and antibody-based therapies may therefore present many benefits to their prevention or cure, as antibodies are inherently evolved to fight off foreign threats.

The lion's share of antibody-based therapies that are already in clinical use or in clinical development are against indications in the areas of oncology, autoimmune diseases, and other chronic diseases [4-6]. To a large extent, this trend is driven by financial incentives and the reality that enterprises operating in the pharmaceutical industry typically must deliver a monetary return on investment to their shareholders. With the traditional business and reimbursement models for pharmaceuticals, achieving financial success may be challenging for antibody-based therapies against many neglected tropical diseases and other infectious diseases, despite the existence of a huge unmet humanitarian need for better therapies in areas such as infectious and parasitic diseases [1,7-11], envenomings by animal bites and stings [12-14], and mushroom poisonings [15]. In these areas, 
existing therapeutic options are either suboptimal, or resistance towards therapy is developing. Although only a few indications within these disease areas are supplied with effective biologics that have reached the clinic, a growing number of studies on the discovery and development of both conventional and advanced antibody-based experimental biotherapeutics have been reported. Moreover, with the general increase in global wealth and the decreasing cost of therapeutic antibody manufacture, it is speculated that antibody-based therapies may become sufficiently cost-competitive to be employed against challenging neglected tropical diseases, such as snakebite envenoming $[16,17]$. In this review, prominent examples of antibody-based therapeutic developments within the areas of viral infections, bacterial infections, parasitic infections, envenomings, and poisonings are reviewed. These examples are followed by an opinion on how novel antibody technologies can better be integrated in the development of a new generation of effective and affordable biotherapies against indications within these disease areas.

\section{New antibody-based therapeutics for neglected tropical diseases and other infectious}

\section{diseases}

\subsection{Viral pathogens}

For decades, researchers have worked on developing monoclonal antibodies against a large number of viral pathogens [18], and with the recent Ebola outbreaks, the search for antibody-based therapeutics against viral indications has gained increased momentum. One of the key challenges with viral pathogens is their ability to undergo rapid mutation and retain their infectivity. Therefore, focus in the viral antibody field is often directed towards development of broadly-neutralizing antibodies against which it is difficult for viruses to create escape mutants [18]. In this relation, human immunodeficiency virus (HIV) has in particular been a challenging indication, although researchers 
have recently reported promising results on the generation of broadly-neutralizing efficacious monoclonal antibodies targeting key epitopes on glycoproteins on the HIV particle [19-22]. Another challenge with viral pathogens is that it can be difficult to predict in vivo efficacy for therapeutic monoclonal antibodies targeting the virus, as in vitro efficacy is not always predictable due to the complex pathogenesis involved in viral infections. This is well exemplified by recent studies on the development of monoclonal antibodies against the alphaviruses, Western equine encephalitis virus (WEEV) [23,24] and Venezuelan equine encephalitis virus (VEEV) [25]. In these studies, humanlike antibodies were developed by phage display technology using scFv antibody libraries derived from macaque monkeys immunized with the viruses. Promising macaque scFvs were selected and genetically fused with fully human $\mathrm{Fc}$ regions to create $\mathrm{scFv}-\mathrm{Fc}$ antibody constructs. Upon expression, several of these antibodies were demonstrated to be able to prevent WEEV or VEEV particles from infecting Vero cells using an in vitro neutralizing peroxidase-linked antibody assay, as well as the antibodies provided protection in vivo in a murine model employing BALB/c mice challenged with virus particles by the airborne route. However, other antibodies, such as ToR67-3B4 and ToR68-2C3, failed to protect in vitro, yet exhibited efficacious neutralizing properties in vivo, possibly due to effective complement-mediated lysis or antibody-dependent cell-mediated lysis of infected cells [23-25]. Despite such challenges for prediction of in vivo efficacy, some antiviral monoclonal antibodies have already reached the market, including Pavilizumab for prevention of respiratory syncytial virus (RSV) infections [26], the recombinant human monoclonal antibody, known as Rabishield, for prevention of rabies [27], and Ibalizumab against HIV [28]. In the future, it is likely that even more antiviral monoclonal antibodies will pass regulatory approval, as a large number of antiviral monoclonal antibodies are currently undergoing evaluation in clinical trials [18].

The discovery and evaluation of therapeutic monoclonal antibodies and antibody fragments has been reported against a number of highly infectious viral tropical diseases, including Sudan Ebola 
virus [29], Zaire Ebola virus [30-33], Nipah virus [34], Hendra virus [35], Dengue virus [36,37], Zika virus [37-40], rotavirus [41], norovirus [42], and Marburg virus [43] (Figure 1). Different antibody discovery methodologies were successfully used in these studies, including hybridoma-based and phage display-based approaches, and the antibodies generated were shown to have efficacy in different preclinical models, including rodents and monkeys, with some antibodies displaying efficacy in clinical trials [41]. Moving on from the discovery and development phase, other important challenges for therapeutic monoclonal antibodies against viral tropical diseases is the high cost of clinical development and the limited market sizes and accessibility [18]. These barriers complicate business planning, which may be one of the reasons why much of the work performed in this field has been undertaken by academics or military research units, sometimes working in collaboration $[24,29,43]$. Finally, therapies based on monoclonal antibodies compete with alternative therapeutic strategies, including vaccination, which is often a more cost-effective approach to achieving patient survival and viral containment [18].

\subsection{Bacterial pathogens}

Before the introduction of antibiotics in the 1930s, bacterial infections were treated with animalderived antisera comprising polyclonal antibodies [44]. These medicines presented a number of drawbacks, including a propensity to elicit adverse reactions due to the immunogenic disposition of the animal antibodies and other proteins present in the antisera, as well as difficulties in standardizing their manufacture and distribution [7]. The treatment of bacterial infections underwent a medical paradigm shift with the advent of antibiotics, such as penicillin, saving millions of lives for both humankind and livestock $[2,45]$. However, with the surge in antibiotic usage in the last many decades, emergence of antimicrobial resistance now represents one of the major threats to human health [1,2]. 
Many of the bacterial pathogens, for which antimicrobial resistance has developed, are not strictly classified as neglected tropical diseases. However, a large number of these disease-inflicting bacteria thrive in the tropics and share many commonalities with more classical neglected tropical diseases, including poor treatment options for patients. The pathogenicity exerted by bacteria responsible for infectious diseases is often facilitated by the colonization of bacteria and production of toxic compounds that disturb homeostasis of the host. Therefore, antibody-based therapies that target key virulence factors (toxins and adhesion/colonization factors) have successfully been developed and approved to combat bacterial infections, such as the human monoclonal antibodies Bezlotoxumab against Clostridium difficile toxin B [44,46], Raxibacumab and Obiltoxaximab against Bacillus anthracis protective antigen (co-administered with antibiotics) [47,48], and Atidortoxumab against Staphylococcus aureus alpha toxin [49]. Common for these therapies is that they all involve intravenous administration of monoclonal immunoglobulin $\mathrm{G}(\mathrm{IgG})$ type antibodies. In the future, other antibody formats and other routes of administration, as well as the use of DNA vaccines, may find their way to the market, both for human and veterinary indications [50-55].

Within the areas of neglected tropical diseases and bacterial infections, a range of different monoclonal antibody formats have been investigated for therapeutic applications. These include humanized IgG, murine IgG, and single-domain monoclonal antibodies against Shiga toxins type 1 and 2 (Stx1 and Stx2) and Shiga-like toxins [56-59], bispecific human monoclonal antibodies against pertussis toxins [60], human monoclonal immunoglobulin A (IgA) antibodies against tuberculosis [61], chimeric IgG antibodies targeting the conserved core/lipid A region of lipopolysaccharide of Vibrio cholerae [62], and human IgM antibodies against endotoxins (lipopolysaccharides, LPS) from gram-negative bacteria involved in sepsis and septic shock [63] (Figure 2). These studies, and many others, demonstrate the applicability of utilizing various different therapeutic approaches to either target the pathogenic bacteria or to neutralize their symptom-inflicting toxins [1]. In this relation, 
there is a hypothetical benefit to targeting key epitopes of the toxins, such as their functional toxic site, instead of targeting the bacteria themselves. Mutants that are able to escape therapeutic intervention are known to evolve for many pathogenic bacteria [2,64]. However, from an evolutionary perspective, it seems less likely for toxins to undergo mutations in their functional site that allow the toxins to avoid recognition by a therapeutic antibody, while still retaining their toxic functionality, than for bacterial escape mutants to evolve. More studies on bacterial and toxin evolution are needed, though, to confirm such a hypothesis.

\subsection{Parasites}

Twelve of the 20 diseases recognized by the World Health Organization as category A neglected tropical diseases are caused by parasites (Table 1) [3]. Additionally, although not included in the category A list of neglected tropical diseases (alongside tuberculosis and HIV, due to substantial and sustained international funding), malaria continues to claim a high number of human lives [65]. Although treatment options are available for some of these diseases, no approved antibody-based therapies currently exist against these indications, and only few reports on therapeutic monoclonal antibodies against parasitic pathogens exist in the scientific literature. Some efforts have, however, been reported on the development of monoclonal IgG antibodies and single-domain antibodies with therapeutic potential against human African trypanosomiasis $[9,54]$. The challenge with parasitic infections is often their ability to evade the mammalian immune response by different mechanisms, which include entering and multiplying within cells, shedding/varying their protein coat, and modulating the immune response of their host [66-68]. For trypanosomiasis, as an example, the parasite achieves this evasion by shedding its VSG coat proteins, followed by expression of other VSG proteins with different antigenic disposition [69,70]. However, in the most recent study on 
antibody-based therapeutics against trypanosomiasis, researchers circumvented this challenge. Here,

547 the development was reported of an antibody-drug conjugate (ADC) targeting the trypanosome 548 haptoglobin-haemoglobin receptor, which was shown to be efficacious against Trypanosoma brucei 549 in a murine infection model [9] (Figure 3). In comparison, the malaria parasite avoids the human 550 immune system by infecting red blood cells and hiding intracellularly. Nevertheless, in a recent study, 551 the discovery of monoclonal human antibodies directed against the Plasmodium falciparum 552 circumsporozoite protein was reported [71]. These antibodies were isolated from several human 553 subjects that had been immunized with an attenuated Pf whole-sporozoite vaccine, and the antibodies 554 were demonstrated to provide in vivo protection in two different mouse models of malaria infection $555[71]$.

In contrast to the therapeutic field, the field of parasite diagnostics has seen the development of a range of monoclonal antibodies against many of the neglected tropical diseases caused by parasites, including schistosomiasis [72], echinococcosis [73], taeniasis [74], leishmaniasis 559 [75], lymphatic filariasis [76], and onchocerciasis [77]. These and other diagnostic developments may indeed help improve patient stratification, clinical diagnosis, and overall patient care within parasitology. However, monoclonal antibodies for diagnostic purposes seldom fulfill the requirements for therapeutic monoclonal antibodies that are used invasively, and a need thus remains for more research and development of antibody-based therapies against parasitic diseases.

566 Envenomings are caused by animals that possess venoms, which are mixtures of protein-based toxins. 567 These toxins are typically evolved for predation purposes, although some animal venoms have also evolved to have a defensive function [12,78]. Classical signs of envenoming from venomous animals, 
such as snakes, scorpions, spiders, bees, fish, centipedes, jellyfish, and other creatures may include neurotoxicity, hemotoxicity, nephrotoxicity, cytotoxicity, myotoxicity, and other less common toxicities. These toxicities may clinically manifest themselves as ptosis, flaccid paralysis, coagulopathies, hemorrhage, necrosis, acute kidney injury, rhabdomyolysis, edema, blistering, inflammation, pain, and shock $[12,13,79,80]$. Venoms may also induce anaphylaxis due to their proteinaceous and sometimes immunogenic dispositions [81-83]. The clinical manifestations of envenomings caused by venomous animals may share some similarities with the clinical manifestations caused by infectious diseases. However, there are several essential differences between these pathophysiologies that have a large impact on what therapeutic strategies may be viable for treating envenoming. Five highly important differences exist:

Firstly, there is no incubation period for amplification of the disease-causing agent, as the entire dose of venom is injected instantaneously. There may, however, be a delay in pathogenesis, if the venom toxins are systemically-acting and need to leave the bite/sting site to exert their toxic actions (e.g. neurotoxins and hemotoxins), known as the depot effect. This has the implication that intervention is exceptionally urgently needed, and that envenomings must be treated as critical emergencies. Secondly, the toxin loads from envenomings by larger venomous animals are delivered immediately and can be pharmacologically enormous. As an example, larger snakes can deliver up to 2.5 gram (dry weight) of venom toxins with molecular weights of 5-100 $\mathrm{kDa}$. This has the implication that exceptionally high amounts of antitoxin (up to 15+ gram dry weight antibody protein) may be needed for successful treatment [84]. This further has the consequence that cost of manufacture has a high impact on what therapeutic modalities are economically feasible, as most animal envenomings occur in poor communities in the rural tropics $[17,85,86]$. Thirdly, animal venoms are highly complex, comprising tens to hundreds of different toxins. This has the implication that mixtures of antitoxins are likely to be needed against most envenomings, and that antivenom 
developers should carefully consider which venom components are medically important to neutralize, and which are not, to minimize the complexity of the therapeutic intervention [87-89]. Fourthly, envenomings are not infectious and therefore only carry a risk to the envenomed victim. This has the implication that the utility of vaccination is limited, if at all existent, as there is no benefit of herd immunity and no risk of uncontrollable epidemic outbreaks. Finally, animals evolve significantly slower than microorganisms and viruses. This has the fortunate implication that medically relevant toxin mutations and the development of resistance against treatment is unlikely to occur for thousands of years.

Animal envenomings are currently still treated using polyclonal antibodies derived from the plasma of hyper-immunized animals (horses, sheep, donkeys, and occasionally rabbits) $[12,13,79,90]$. When properly manufactured, these life-saving medicines are effective in neutralizing animal venoms. However, due to their heterologous nature, they have a propensity to cause immunological reactions in human recipients [90]. To circumvent this challenge of immunogenicity, and to improve other therapeutic properties, such as enhancing efficacy and reducing batch-to-batch variation, researchers worldwide have started to embrace different antibody technologies with the goal of developing recombinant antivenoms [89,91,92]. Recently, the discovery of the first fully human oligoclonal IgGs against animal toxins was reported [93]. Here, it was demonstrated that phage display selection employing naïve human antibody libraries could be exploited to discover mixtures of human monoclonal IgGs that could abrogate dendrotoxin-mediated neurotoxicity of black mamba (Dendroaspis polylepis) whole venom in vivo [93]. Also, other researchers have recently reported the discovery of human monoclonal scFvs that can broadly neutralize toxins from multiple scorpion species $[94,95]$, as well as it has been shown that experimental antivenoms based on nanobodies and nanobody-constructs can be used to effectively neutralize snake toxins and venoms [96,97]. These and other recent results in antibody discovery within animal envenomings $[90,98]$ 
(Figure 4) now warrant further development efforts within envenoming therapy. However, the path towards the approval and marketing of fundamentally novel antivenom products is likely to be long, complicated, and require significant support and international collaboration [14,84], as the field of next-generation envenoming therapeutics is still in its infancy.

\subsection{Mushroom poisonings}

Mushroom poisonings occur across tropical, subtropical, and temperate climates, but share some similar characteristics with animal envenomings and neglected tropical diseases and have thus been included in this review. About 5000 different species of mushrooms exist, with about 50 species being poisonous to humans [15]. In contrast to venom toxins that due to their size and proteinaceous nature are unable to be absorbed in the gastrointestinal tract, mushroom poisons comprise small oligopeptidic toxins that can be readily absorbed in the gastrointestinal tract and are thus toxic when ingested [91]. Most of the mushroom species involved in lethal poisonings are found in the genus Amanita, which produces amatoxins, phallotoxins, and virotoxins [99]. Of these toxins, the amatoxins are of highest medical concern, and they retain their potent hepatotoxicity even upon boiling. Their mode of action involves inhibition of the RNA polymerase II, responsible for transcription of mRNA [100]. Even today, the treatment options for mushroom poisonings caused by amatoxins remain inadequate and severe cases of poisoning can necessitate liver transplantation [101-105]. Despite their small size, amatoxins may invoke an immune response, and researchers have reported the development of both IgG and Fab-based monoclonal antibodies using hybridoma technology [106]. Interestingly, when these two different antibody formats were assessed for their ability to neutralize amatoxins in a murine model, it was discovered that instead of neutralizing the toxins, both antibody types enhanced toxicity. Particularly, the Fab antibody was shown to dramatically enhance toxicity 
640

641

642

50-fold, as the Fab antibody increased accumulation of the toxin in the kidneys, causing major nephrotoxicity [106]. More than a decade ago, it was reported that attempts to use antibody-based therapies against mushroom poisonings had not been successful [15], and to the best of my knowledge this finding remains the status quo. It is thus uncertain whether effective antibody-based therapeutics may ever find their way into the field of mushroom poisoning, however, the possibility cannot be entirely excluded. Some of the many recently developed advanced antibody formats, such as bispecifics and novel binding protein scaffolds, may offer improved or entirely different mechanisms of action and pharmacokinetics that might find their utility in mushroom poisoning therapy.

\section{Conclusion}

A number of therapies against infectious diseases based on monoclonal antibodies have found their way to the market in recent years $[18,44,46-49]$. These approved therapies all fall within the areas of bacterial and viral infections $[1,8]$. In contrast, the development of therapeutic monoclonal antibodies against parasitic diseases, animal envenomings, and mushroom poisonings is far behind, although recent reports within trypanosomiasis therapy and recombinant antivenoms against snakebite and scorpion envenoming demonstrate potential and utility of employing antibody technologies in these fields $[9,93,95]$. The reason for the disparity in the development stages between these two groups (bacterial and viral infectious diseases vs. parasitic diseases, animal envenomings, and mushroom poisonings) may possibly be found in their potential for causing uncontainable epidemic outbreaks coupled to the limited commercial prospects that may exist for the latter group of diseases.

\section{Expert opinion}


Public interest and increased institutional focus on the United Nation's Sustainable Development Goals has brought renewed attention to the global challenges for humankind. Combined with the rapid development of antibody discovery and manufacturing technologies, this may create an opening for bringing antibody-based therapies against neglected tropical diseases and other infectious diseases to life. The antibody developer may piggy-back on the many scientific and technological achievements from the fields of oncology and autoimmune diseases [85], which can be exploited to reap the many technologically low-hanging fruits that exist in the field of neglected tropical diseases due to the lack of prior art. This creates an opportunity for the academic scientist who is evaluated more on his or her ability to perform and publish high impact science than on his or her ability to drive scientifically incremental, yet profitable, development. Specifically, the field of antibody-based therapies against neglected tropical diseases may constitute a possibility for countries in the developing tropics to establish scientific environments and build research capacity and excellence in "blue ocean" fields, allowing them to become global leaders in certain scientific areas that are not already dominated by countries and institutions in the US, Europe, or elsewhere. Neglected tropical diseases and other infectious diseases, as well as envenomings and poisonings caused by animals and mushrooms, are in many ways fundamentally different than oncology and autoimmune diseases with endogenous disease targets. These differences include the therapeutic targets being exogenous and numerous in numbers for given indications (due to hypermutability and presence of multitudes of toxins), as well as the target markets being less profitable and difficult to enter. Antibody discoverers within these fields may therefore be forced to be creative and develop entirely new antibody-based therapeutic approaches and pharmacological mechanisms of action. In turn, this may open up for the possibility of treating currently untreatable diseases or developing next-generation therapies of unprecedented efficacy in fields with suboptimal treatment options. The fields of neglected tropical diseases, other infectious diseases, and intoxications may even represent a scientific Eldorado for 
areas such as understanding and designing cross-reactivity for monoclonal antibodies [107], use of 687 oligoclonal antibody cocktails for multi-target neutralization [1,17,108], novel immunization 688 approaches [109], targeting of evasive pathogens [9,10], and exploitation of novel therapeutic 689 mechanisms of action [41]. Such potential developments will likely be further catalyzed by advances 690 in antibody production technologies that may enable low cost of antibody manufacture $[17,110]$ and, 691 in turn, better affordability of antibody-based therapies on a global scale. Despite their currently 692 overlooked status, neglected tropical diseases, other infectious diseases, and intoxications may one 693 day find themselves in the limelight of antibody developers, who may recognize the potential for 694 improving therapies for victims worldwide, while simultaneously experimenting with innovative 695 antibody-based approaches and elucidating fundamentally novel antibody properties. 
698 699

[1] Wagner EK, Maynard JA. Engineering therapeutic antibodies to combat infectious diseases. Curr. Opin. Chem. Eng. 2018;19:131-141.

[2] Ventola CL. The Antibiotic Resistance Crisis. Pharm. Ther. 2015;40:277-283.

[3] Standley C, Boyce MR, Klineberg A, et al. Organization of oversight for integrated control of neglected tropical diseases within Ministries of Health. PLoS Negl. Trop. Dis. 2018;12:e0006929.

[4] Walsh G. Biopharmaceutical benchmarks 2018. Nat. Biotechnol. 2018;36:1136-1145.

** This review provides a comprehensive overview of the state-of-the-art in the field of biopharmaceuticals

[5] Kaplon H, Reichert JM. Antibodies to watch in 2019. mAbs. 2019;11:219-238.

* This review describes the newest trends and developments within therapeutic monoclonal antibodies

[6] Strohl WR. Current progress in innovative engineered antibodies. Protein Cell. 2018;9:86-120.

[7] Sparrow E, Friede M, Sheikh M, et al. Therapeutic antibodies for infectious diseases. Bull. World Health Organ. 2017;95:235-237.

[8] Marston HD, Paules Cl, Fauci AS. Monoclonal Antibodies for Emerging Infectious Diseases - Borrowing from History. N. Engl. J. Med. 2018;378:1469-1472.

[9] MacGregor P, Gonzalez-Munoz AL, Jobe F, et al. A single dose of antibody-drug conjugate cures a stage 1 model of African trypanosomiasis. bioRxiv. 2019;547208.

** This article describes how an antibody drug conjugate was developed to effectively kill the parasite, Trypanosoma brucei, in vivo

[10] Sok D, Burton DR. Recent progress in broadly neutralizing antibodies to HIV. Nat. Immunol. 2018;19:1179.

[11] Maruyama T, Parren PWHI, Sanchez A, et al. Recombinant Human Monoclonal Antibodies to Ebola Virus. J. Infect. Dis. 1999;179:S235-S239.

[12] Gutiérrez JM, Calvete JJ, Habib AG, et al. Snakebite envenoming. Nat. Rev. Dis. Primer. 2017;3:17063.

* This review provides a comprehensive overview of the field of snakebite envenoming and its treatment

[13] Laustsen AH, Solà M, Jappe EC, et al. Biotechnological Trends in Spider and Scorpion Antivenom Development. Toxins. 2016;8.

[14] Williams DJ, Faiz MA, Abela-Ridder B, et al. Strategy for a globally coordinated response to a priority neglected tropical disease: Snakebite envenoming. PLoS Negl. Trop. Dis. 2019;13:e0007059.

[15] Broussard CN, Aggarwal A, Lacey SR, et al. Mushroom poisoning--from diarrhea to liver transplantation. Am. J. Gastroenterol. 2001;96:3195-3198. 
[16] Laustsen $\mathrm{AH}$, Johansen $\mathrm{KH}$, Engmark M, et al. Snakebites: costing recombinant antivenoms. Nature. 2016;538:41.

[17] Laustsen $\mathrm{AH}$, Johansen $\mathrm{KH}$, Engmark $\mathrm{M}$, et al. Recombinant snakebite antivenoms: A cost-competitive solution to a neglected tropical disease? PLoS Negl. Trop. Dis. 2017;11:e0005361.

** This article provides cost calculations for the manufacture of therapeutic monoclonal and oligoclonal antibodies for use as recombinant antivenom

[18] Salazar G, Zhang N, Fu T-M, et al. Antibody therapies for the prevention and treatment of viral infections. NPJ Vaccines [Internet]. 2017 [cited 2019 Apr 8];2. Available from: https://www.ncbi.nlm.nih.gov/pmc/articles/PMC5627241/.

[19] Kong R, Louder MK, Wagh K, et al. Improving neutralization potency and breadth by combining broadly reactive HIV-1 antibodies targeting major neutralization epitopes. J. Virol. 2015;89:26592671.

* This study demonstrates that the neutralization potential of monoclonal antibodies targeting HIV can be improved by utilizing cocktails of monoclonal antibodies

[20] Wibmer CK, Richardson SI, Yolitz J, et al. Common helical V1V2 conformations of HIV-1 Envelope expose the $\alpha 4 \beta 7$ binding site on intact virions. Nat. Commun. 2018;9:4489.

[21] Lertjuthaporn S, Cicala C, Van Ryk D, et al. Select gp120 V2 domain specific antibodies derived from HIV and SIV infection and vaccination inhibit gp120 binding to $\alpha 4 \beta 7$. PLoS Pathog. 2018;14:e1007278.

[22] van Eeden C, Wibmer CK, Scheepers C, et al. V2-Directed Vaccine-like Antibodies from HIV-1 Infection Identify an Additional K169-Binding Light Chain Motif with Broad ADCC Activity. Cell Rep. 2018;25:3123-3135.e6.

[23] Hülseweh B, Rülker T, Pelat T, et al. Human-like antibodies neutralizing Western equine encephalitis virus. mAbs. 2014;6:718-727.

[24] Burke CW, Froude JW, Miethe S, et al. Human-Like Neutralizing Antibodies Protect Mice from Aerosol Exposure with Western Equine Encephalitis Virus. Viruses. 2018;10.

[25] Rülker T, Voß L, Thullier $P$, et al. Isolation and characterisation of a human-like antibody fragment (scFv) that inactivates VEEV in vitro and in vivo. PloS One. 2012;7:e37242.

[26] American Academy of Pediatrics Committee on Infectious Diseases and Committee on Fetus and Newborn. Revised indications for the use of palivizumab and respiratory syncytial virus immune globulin intravenous for the prevention of respiratory syncytial virus infections. Pediatrics. 2003;112:1442-1446.

[27] Gogtay NJ, Munshi R, Ashwath Narayana DH, et al. Comparison of a Novel Human Rabies Monoclonal Antibody to Human Rabies Immunoglobulin for Postexposure Prophylaxis: A Phase 2/3, Randomized, Single-Blind, Noninferiority, Controlled Study. Clin. Infect. Dis. Off. Publ. Infect. Dis. Soc. Am. 2018;66:387-395. 
[28] Jacobson JM, Kuritzkes DR, Godofsky E, et al. Safety, Pharmacokinetics, and Antiretroviral Activity of Multiple Doses of Ibalizumab (formerly TNX-355), an Anti-CD4 Monoclonal Antibody, in Human Immunodeficiency Virus Type 1-Infected Adults. Antimicrob. Agents Chemother. 2009;53:450-457.

[29] Froude JW, Herbert AS, Pelat T, et al. Post-Exposure Protection in Mice against Sudan Virus by a Two Antibody Cocktail. Viruses. 2018;10.

[30] Qiu X, Audet J, Lv M, et al. Two-mAb cocktail protects macaques against the Makona variant of Ebola virus. Sci. Transl. Med. 2016;8:329ra33.

[31] PREVAIL II Writing Group, Multi-National PREVAIL II Study Team, Davey RT, et al. A Randomized, Controlled Trial of ZMapp for Ebola Virus Infection. N. Engl. J. Med. 2016;375:1448-1456.

* This article describes a clinical study, in which a cocktail of monoclonal antibodies was assessed for its efficacy against Ebola. Unfortunately, the cocktail failed to meet the threshold for efficacy.

[32] Saphire EO, Schendel SL, Fusco ML, et al. Systematic Analysis of Monoclonal Antibodies against Ebola Virus GP Defines Features that Contribute to Protection. Cell. 2018;174:938-952.e13.

[33] van Lieshout LP, Soule G, Sorensen D, et al. Intramuscular Adeno-Associated Virus-Mediated Expression of Monoclonal Antibodies Provides 100\% Protection Against Ebola Virus Infection in Mice. J. Infect. Dis. 2018;217:916-925.

[34] Zhu Z, Dimitrov AS, Bossart KN, et al. Potent Neutralization of Hendra and Nipah Viruses by Human Monoclonal Antibodies. J. Virol. 2006;80:891-899.

[35] Bossart KN, Geisbert TW, Feldmann H, et al. A neutralizing human monoclonal antibody protects african green monkeys from hendra virus challenge. Sci. Transl. Med. 2011;3:105ra103.

[36] Wan S-W, Chen P-W, Chen C-Y, et al. Therapeutic Effects of Monoclonal Antibody against Dengue Virus NS1 in a STAT1 Knockout Mouse Model of Dengue Infection. J. Immunol. Baltim. Md 1950. 2017;199:2834-2844.

[37] Swanstrom JA, Plante JA, Plante KS, et al. Dengue Virus Envelope Dimer Epitope Monoclonal Antibodies Isolated from Dengue Patients Are Protective against Zika Virus. mBio. 2016;7.

[38] Bailey MJ, Broecker F, Duehr J, et al. Antibodies Elicited by an NS1-Based Vaccine Protect Mice against Zika Virus. mBio. 2019;10.

[39] Fernandez E, Dejnirattisai W, Cao B, et al. Human antibodies to the dengue virus E-dimer epitope have therapeutic activity against Zika virus infection. Nat. Immunol. 2017;18:1261-1269.

[40] Wang L, Wang R, Wang L, et al. Structural Basis for Neutralization and Protection by a Zika VirusSpecific Human Antibody. Cell Rep. 2019;26:3360-3368.e5.

[41] Sarker SA, Jäkel M, Sultana S, et al. Anti-Rotavirus Protein Reduces Stool Output in Infants With Diarrhea: A Randomized Placebo-Controlled Trial. Gastroenterology. 2013;145:740-748.e8.

** This clinical study demonstrates the efficacy of a nanobody-based intervention against rota virusinduced infant diarrhea 
[42] Alvarado G, Ettayebi K, Atmar RL, et al. Human Monoclonal Antibodies That Neutralize Pandemic GIl.4 Noroviruses. Gastroenterology. 2018;155:1898-1907.

[43] Froude JW, Pelat T, Miethe S, et al. Generation and characterization of protective antibodies to Marburg virus. mAbs. 2017;9:696-703.

[44] Hey A. History and Practice: Antibodies in Infectious Diseases. Microbiol. Spectr. 2015;3:AID-00262014.

[45] Marshall BM, Levy SB. Food Animals and Antimicrobials: Impacts on Human Health. Clin. Microbiol. Rev. 2011;24:718-733.

[46] Navalkele BD, Chopra T. Bezlotoxumab: an emerging monoclonal antibody therapy for prevention of recurrent Clostridium difficile infection. Biol. Targets Ther. 2018;12:11-21.

[47] Migone T-S, Subramanian GM, Zhong J, et al. Raxibacumab for the Treatment of Inhalational Anthrax. N. Engl. J. Med. 2009;361:135-144.

[48] Yamamoto BJ, Shadiack AM, Carpenter S, et al. Obiltoxaximab Prevents Disseminated Bacillus anthracis Infection and Improves Survival during Pre- and Postexposure Prophylaxis in Animal Models of Inhalational Anthrax. Antimicrob. Agents Chemother. 2016;60:5796-5805.

[49] WHO Drug Information Vol. 31, No. 2, 2017 - Proposed International Nonproprietary Names, List 117 [Internet]. [cited 2019 Apr 9]. Available from:

http://apps.who.int/medicinedocs/en/m/abstract/Js23256en/.

[50] Siontorou CG. Nanobodies as novel agents for disease diagnosis and therapy. Int. J. Nanomedicine. 2013;8:4215-4227.

[51] Moonens K, Kerpel MD, Coddens A, et al. Nanobody Mediated Inhibition of Attachment of F18 Fimbriae Expressing Escherichia coli. PLOS ONE. 2014;9:e114691.

[52] Moonens K, Van den Broeck I, Okello E, et al. Structural insight in the inhibition of adherence of F4 fimbriae producing enterotoxigenic Escherichia coli by llama single domain antibodies. Vet. Res. [Internet]. 2015 [cited 2019 Apr 9];46. Available from: https://www.ncbi.nlm.nih.gov/pmc/articles/PMC4337312/.

[53] Unger M, Eichhoff AM, Schumacher L, et al. Selection of Nanobodies that Block the Enzymatic and Cytotoxic Activities of the Binary Clostridium Difficile Toxin CDT. Sci. Rep. [Internet]. 2015 [cited 2019 Apr 9];5. Available from: https://www.ncbi.nlm.nih.gov/pmc/articles/PMC4297958/.

[54] Fernandes CFC, Pereira SDS, Luiz MB, et al. Camelid Single-Domain Antibodies As an Alternative to Overcome Challenges Related to the Prevention, Detection, and Control of Neglected Tropical Diseases. Front. Immunol. 2017;8:653.

[55] Liu S, Wang S, Lu S. DNA immunization as a technology platform for monoclonal antibody induction. Emerg. Microbes Infect. 2016;5:e33.

[56] Skinner C, Patfield S, Stanker LH, et al. New high-affinity monoclonal antibodies against Shiga toxin 1 facilitate the detection of hybrid Stx1/Stx2 in vivo. PloS One. 2014;9:e99854. 
[57] Smith MJ, Melton-Celsa AR, Sinclair JF, et al. Monoclonal antibody 11E10, which neutralizes shiga toxin type 2 (Stx2), recognizes three regions on the Stx2 A subunit, blocks the enzymatic action of the toxin in vitro, and alters the overall cellular distribution of the toxin. Infect. Immun. 2009;77:27302740.

[58] López EL, Contrini MM, Glatstein E, et al. Safety and pharmacokinetics of urtoxazumab, a humanized monoclonal antibody, against Shiga-like toxin 2 in healthy adults and in pediatric patients infected with Shiga-like toxin-producing Escherichia coli. Antimicrob. Agents Chemother. 2010;54:239-243.

[59] Mejías MP, Hiriart Y, Lauché C, et al. Development of camelid single chain antibodies against Shiga toxin type 2 (Stx2) with therapeutic potential against Hemolytic Uremic Syndrome (HUS). Sci. Rep. 2016;6:24913.

[60] Wagner EK, Wang X, Bui A, et al. Synergistic Neutralization of Pertussis Toxin by a Bispecific Antibody In Vitro and In Vivo. Clin. Vaccine Immunol. CVI. 2016;23:851-862.

* This study demonstrates that a bispecific antibody can effectively neutralize pertussis toxin in vitro and in vivo

[61] Balu S, Reljic R, Lewis MJ, et al. A Novel Human IgA Monoclonal Antibody Protects against Tuberculosis. J. Immunol. 2011;186:3113-3119.

[62] Levinson KJ, Baranova DE, Mantis NJ. A monoclonal antibody that targets the conserved core/lipid A region of lipopolysaccharide affects motility and reduces intestinal colonization of both classical and El Tor Vibrio cholerae biotypes. Vaccine. 2016;34:5833-5836.

[63] Hinds CJ. Monoclonal antibodies in sepsis and septic shock. BMJ. 1992;304:132-133.

[64] Read AF, Woods RJ. Antibiotic resistance management. Evol. Med. Public Health. 2014;2014:147.

[65] Cibulskis RE, Alonso P, Aponte J, et al. Malaria: Global progress $2000-2015$ and future challenges. Infect. Dis. Poverty. 2016;5:61.

[66] Schmid-Hempel Paul. Immune defence, parasite evasion strategies and their relevance for 'macroscopic phenomena' such as virulence. Philos. Trans. R. Soc. B Biol. Sci. 2009;364:85-98.

[67] Zambrano-Villa S, Rosales-Borjas D, Carrero JC, et al. How protozoan parasites evade the immune response. Trends Parasitol. 2002;18:272-278.

[68] Cox FEG. How parasites evade the immune response. Immunol. Today. 1984;5:32-33.

[69] Berriman M, Ghedin E, Hertz-Fowler C, et al. The Genome of the African Trypanosome Trypanosoma brucei. Science. 2005;309:416-422.

[70] Seyfang A, Mecke D, Duszenko M. Degradation, Recycling, and Shedding of Trypanosoma brucei Variant Surface Glycoprotein. J. Protozool. 1990;37:546-552.

[71] Kisalu NK, Idris AH, Weidle C, et al. A human monoclonal antibody prevents malaria infection by targeting a new site of vulnerability on the parasite. Nat. Med. 2018;24:408-416. 
** This study demonstrates that human monoclonal antibodies can be utilized to prevent malaria infection in vivo

[72] Shaker ZA, Kaddah MA, Hanallah SB, et al. Production of monoclonal antibodies against target schistosomal antigen secreted in the urine of Schistosoma mansoni-infected patients. Int. J. Parasitol. 1998;28:1893-1901.

[73] Casaravilla C, Malgor R, Rossi A, et al. Production and characterization of monoclonal antibodies against excretory/secretory products of adult Echinococcus granulosus, and their application to coproantigen detection. Parasitol. Int. 2005;54:43-49.

[74] Paredes A, Sáenz P, Marzal MW, et al. Anti-Taenia solium monoclonal antibodies for the detection of parasite antigens in body fluids from patients with neurocysticercosis. Exp. Parasitol. 2016;166:37-43.

[75] Nejad-Moghaddam A, Abolhassani M. Production and characterization of monoclonal antibodies recognizing a common 57-kDa antigen of Leishmania species. Iran. Biomed. J. 2009;13:245-251.

[76] Pandey V, Madhumathi J, Karande AA, et al. Antigen detection assay with parasite specific monoclonal antibodies for diagnosis of Iymphatic filariasis. Clin. Chim. Acta. 2011;412:1867-1873.

[77] Cho-Ngwa F, Daggfeldt A, Titanji VPK, et al. Preparation and characterization of specific monoclonal antibodies for the detection of adult worm infections in onchocerciasis. Hybrid. 2005. 2005;24:283290.

[78] Fry BG, Roelants K, Norman JA. Tentacles of Venom: Toxic Protein Convergence in the Kingdom Animalia. J. Mol. Evol. 2009;68:311-321.

[79] Laustsen AH, Engmark M, Milbo C, et al. From Fangs to Pharmacology: The Future of Snakebite Envenoming Therapy. Curr. Pharm. Des. 2016;22:5270-5293.

* This review provides a comprehensive overview of all therapeutic developments within the use of antibodies, small molecules inhibitors, and innovative immunization approaches for the development of novel snakebite envenoming therapies

[80] Undheim EAB, Fry BG, King GF. Centipede Venom: Recent Discoveries and Current State of Knowledge. Toxins. 2015;7:679-704.

[81] Busse WW, Reed CE, Lichtenstein LM, et al. Immunotherapy in Bee-Sting Anaphylaxis: Use of Honeybee Venom. JAMA. 1975;231:1154-1156.

[82] Ryan KC, Martin Caravati E. Life-threatening anaphylaxis following envenomation by two different species of Crotalidae. J. Wilderness Med. 1994;5:263-268.

[83] León G, Sánchez L, Hernández A, et al. Immune response towards snake venoms. Inflamm. Allergy Drug Targets. 2011;10:381-398.

[84] Harrison RA, Gutiérrez JM. Priority actions and progress to substantially and sustainably reduce the mortality, morbidity and socioeconomic burden of tropical snakebite. Toxins. 2016;8.

[85] Laustsen AH, Dorrestijn N. Integrating Engineering, Manufacturing, and Regulatory Considerations in the Development of Novel Antivenoms. Toxins. 2018;10:309. 
[86] Harrison RA, Hargreaves A, Wagstaff SC, et al. Snake Envenoming: A Disease of Poverty. PLoS Negl. Trop. Dis. [Internet]. 2009 [cited 2016 Aug 17];3. Available from: http://www.ncbi.nlm.nih.gov/pmc/articles/PMC2791200/.

[87] Laustsen AH, Lohse B, Lomonte B, et al. Selecting key toxins for focused development of elapid snake antivenoms and inhibitors guided by a Toxicity Score. Toxicon. 2015;104:43-45.

[88] Laustsen AH. Toxin synergism in snake venoms. Toxin Rev. 2016;35:165-170.

[89] Laustsen AH. Guiding recombinant antivenom development by omics technologies. New Biotechnol. 2018;45:19-27.

[90] Laustsen AH, Gutiérrez JM, Knudsen C, et al. Pros and cons of different therapeutic antibody formats for recombinant antivenom development. Toxicon. 2018;146:151-175.

** This review provides a comprehensive overview of the benefits and drawbacks of different antibody formats in relation to snakebite envenoming therapy

[91] Laustsen AH. Recombinant antivenoms. 1st ed. Copenhagen, Denmark: University of Copenhagen; 2016.

[92] Kini RM, Sidhu SS, Laustsen AH. Biosynthetic Oligoclonal Antivenom (BOA) for Snakebite and NextGeneration Treatments for Snakebite Victims. Toxins. 2018;10:534.

[93] Laustsen AH, Karatt-Vellatt A, Masters EW, et al. In vivo neutralization of dendrotoxin-mediated neurotoxicity of black mamba venom by oligoclonal human IgG antibodies. Nat. Commun. 2018;9:3928.

** This study demonstrates the therapeutic utility of using oligoclonal human IgG antibodies for the neutralization of black mamba venom in vivo

[94] Rodríguez-Rodríguez ER, Olamendi-Portugal T, Serrano-Posada $\mathrm{H}$, et al. Broadening the neutralizing capacity of a family of antibody fragments against different toxins from Mexican scorpions. Toxicon. 2016;119:52-63.

[95] Riaño-Umbarila L, Gómez-Ramírez IV, Ledezma-Candanoza LM, et al. Generation of a Broadly CrossNeutralizing Antibody Fragment against Several Mexican Scorpion Venoms. Toxins. 2019;11:32.

* This study demonstrates how broadly neutralizing monoclonal antibodies can be developed against medically important scorpion toxins

[96] Julve Parreño JM, Huet E, Fernández-Del-Carmen A, et al. A synthetic biology approach for consistent production of plant-made recombinant polyclonal antibodies against snake venom toxins. Plant Biotechnol. J. 2017;

[97] Richard G, Meyers AJ, McLean MD, et al. In Vivo Neutralization of $\alpha$-Cobratoxin with High-Affinity Llama Single-Domain Antibodies (VHHs) and a VHH-Fc Antibody. Ho PL, editor. PLoS ONE. 2013;8:e69495.

[98] Knudsen C, Laustsen AH. Recent Advances in Next Generation Snakebite Antivenoms. Trop. Med. Infect. Dis. 2018;3:42. 
[99] Vetter J. Toxins of Amanita phalloides. Toxicon. 1998;36:13-24.

[100] Karlson-Stiber C, Persson H. Cytotoxic fungi-an overview. Toxicon. 2003;42:339-349.

[101] Klein AS, Hart J, Brems JJ, et al. Amanita poisoning: treatment and the role of liver transplantation. Am. J. Med. 1989;86:187-193.

[102] Bonacini M, Shetler K, Yu I, et al. Features of Patients With Severe Hepatitis Due to Mushroom Poisoning and Factors Associated With Outcome. Clin. Gastroenterol. Hepatol. 2017;15:776-779.

[103] Karvellas CJ, Tillman $\mathrm{H}$, Leung $A A$, et al. Acute liver injury and acute liver failure from mushroom poisoning in North America. Liver Int. 2016;36:1043-1050.

[104] Schmutz M, Carron P-N, Yersin B, et al. Mushroom poisoning: a retrospective study concerning 11-years of admissions in a Swiss Emergency Department. Intern. Emerg. Med. 2018;13:59-67.

[105] White J, Weinstein SA, De Haro L, et al. Mushroom poisoning: A proposed new clinical classification. Toxicon. 2019;157:53-65.

[106] Faulstich H, Kirchner K, Derenzini M. Strongly enhanced toxicity of the mushroom toxin alpha-amanitin by an amatoxin-specific Fab or monoclonal antibody. Toxicon. 1988;26:491-499.

** This study demonstrates the complexities in using therapeutic monoclonal antibodies against poisonings cause by mushroom toxins

[107] Ledsgaard L, Jenkins TP, Davidsen K, et al. Antibody Cross-Reactivity in Antivenom Research. Toxins. 2018;10.

[108] D'Souza JW, Robinson MK. Oligoclonal antibodies to target the ErbB family. Expert Opin. Biol. Ther. 2015;15:1015-1021.

[109] Bermúdez-Méndez E, Fuglsang-Madsen A, Føns S, et al. Innovative Immunization Strategies for Antivenom Development. Toxins. 2018;10:452.

[110] Hammerschmidt N, Tscheliessnig A, Sommer R, et al. Economics of recombinant antibody production processes at various scales: Industry-standard compared to continuous precipitation. Biotechnol. J. 2014;9:766-775.

** This study describes the economics of antibody manufacture in larger scale 
970 Acknowledgments

971 I thank Cecilie Knudsen and Line Ledsgaard from the Technical University of Denmark (Denmark),

972 José María Gutiérrez from Instituto Clodomiro Picado (Costa Rica), and Michael Hust from the

973 University of Braunschweig for scientific discussion in relation to the topic of the manuscript. I also 974 thank Shirin Ahmadi from Eskisehir Osmangazi University (Turkey) for preparation of figures.

975 Finally, I thank the Villum Foundation (grant no. 00025302) for financial support.

976

977 Author contributions

978 The author was singly involved in all aspect of preparing the manuscript.

979

980 Conflict of interest

981 The author declares no conflict of interest. 
Table 1. The 20 diseases listed as Category A Neglected Tropical Diseases by the World Health

\section{Organization.}

\begin{tabular}{|c|c|c|c|}
\hline Viral diseases & Bacterial diseases & Parasitic diseases & Other \\
\hline Dengue & Buruli ulcer & Chagas disease & Snakebite envenoming \\
\hline Chikungunya & Leprosy & Dracunculiasis & \\
\hline \multirow[t]{10}{*}{ Rabies } & Mycetoma* & Echinococcosis & \\
\hline & Trachoma & $\begin{array}{l}\text { Foodborne } \\
\text { trematodiases }\end{array}$ & \\
\hline & Yaws & $\begin{array}{l}\text { Human African } \\
\text { trypanosomiasis }\end{array}$ & \\
\hline & & Leishmaniasis & \\
\hline & & Lymphatic filariasis & \\
\hline & & Onchocerciasis & \\
\hline & & Scabies & \\
\hline & & Schistosomiasis & \\
\hline & & $\begin{array}{l}\text { Soil-transmitted } \\
\text { helminths }\end{array}$ & \\
\hline & & $\begin{array}{l}\text { Taeniasis and } \\
\text { cysticercosis }\end{array}$ & \\
\hline
\end{tabular}

*It is unknown whether mycetoma is caused by bacterial or fungal infection. 
990

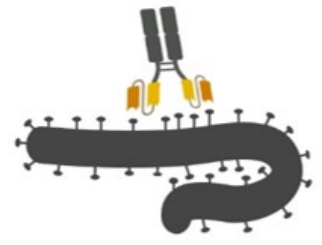

A

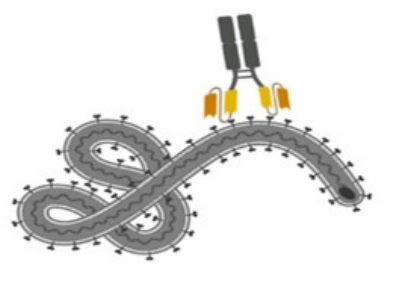

D

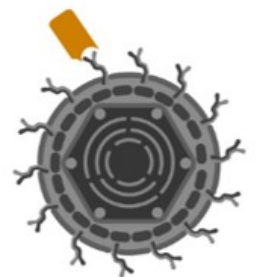

B

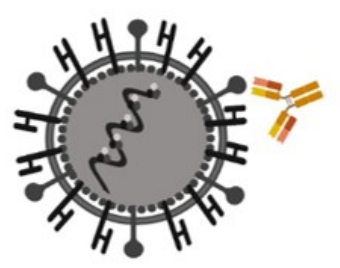

E

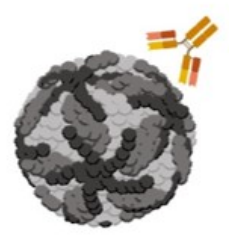

C

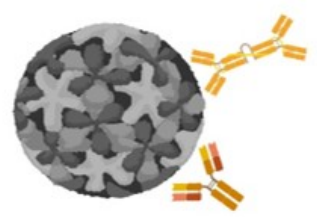

$\mathrm{F}$

Figure 1

993 Conceptual overview of different monoclonal antibody formats that have been reported against 994 selected viral indications. A) IgG-like antibody discovered against Marburg virus. B) $\mathrm{V}_{\mathrm{H}} \mathrm{H}$ antibody 995 fragment discovered against rotavirus. C) IgG antibodies discovered against Dengue and Zika (only 996 one example shown). D) IgG-like antibodies discovered against Sudan and Zaire Ebola virus (only 997 one example shown). E) IgG antibodies discovered against Hendra and Nipah virus (only one 998 example shown). F) IgA and IgG antibodies discovered against norovirus. 


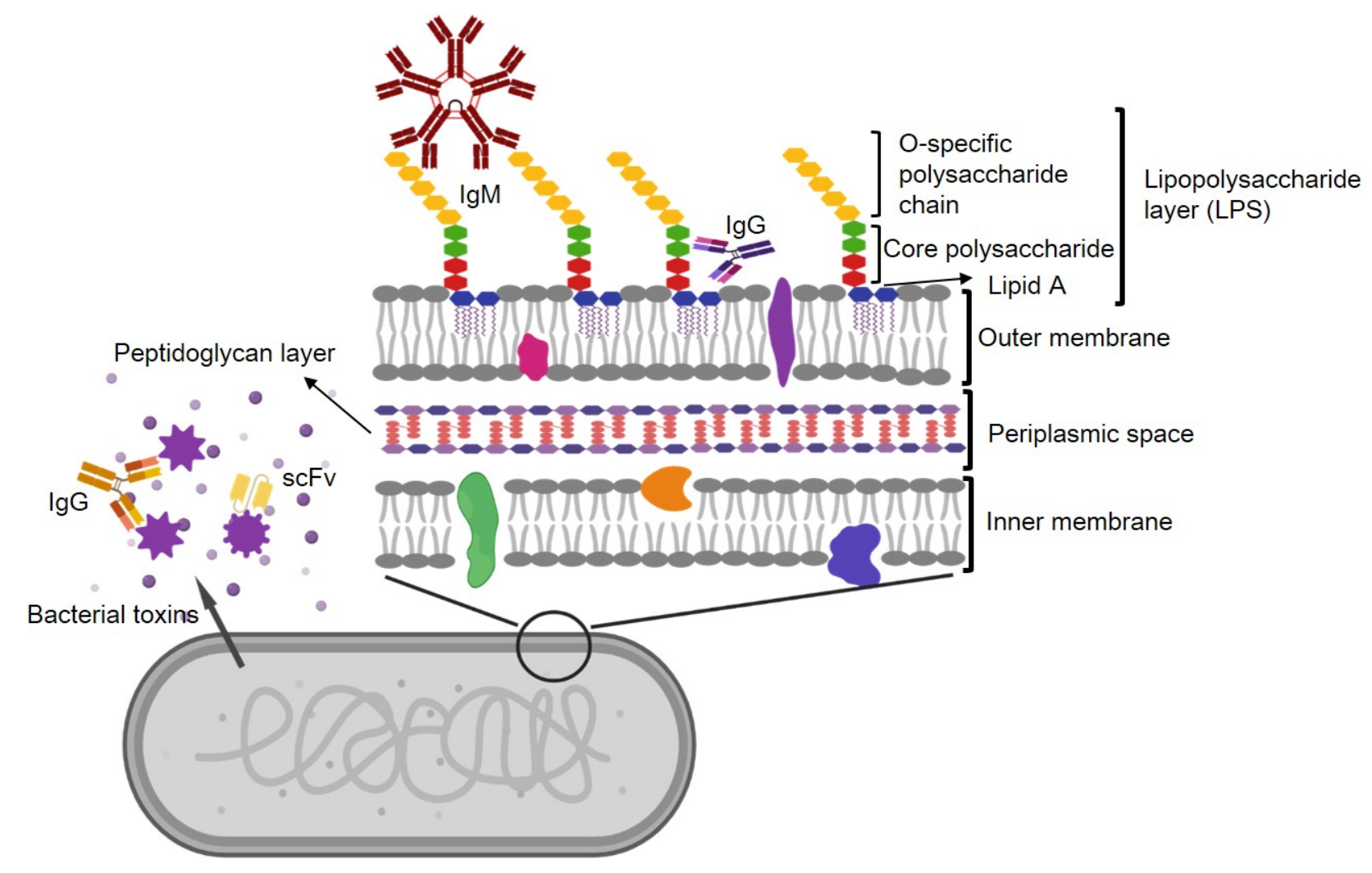

Figure 2

1002 Conceptual and schematic representation of a bacterial cell with a zoom-in on the cell wall. Different 1003 antibody formats (scFv, IgG, and IgM) targeting various therapeutic targets, including 1004 lipopolysaccharides and bacterial toxins are depicted. 


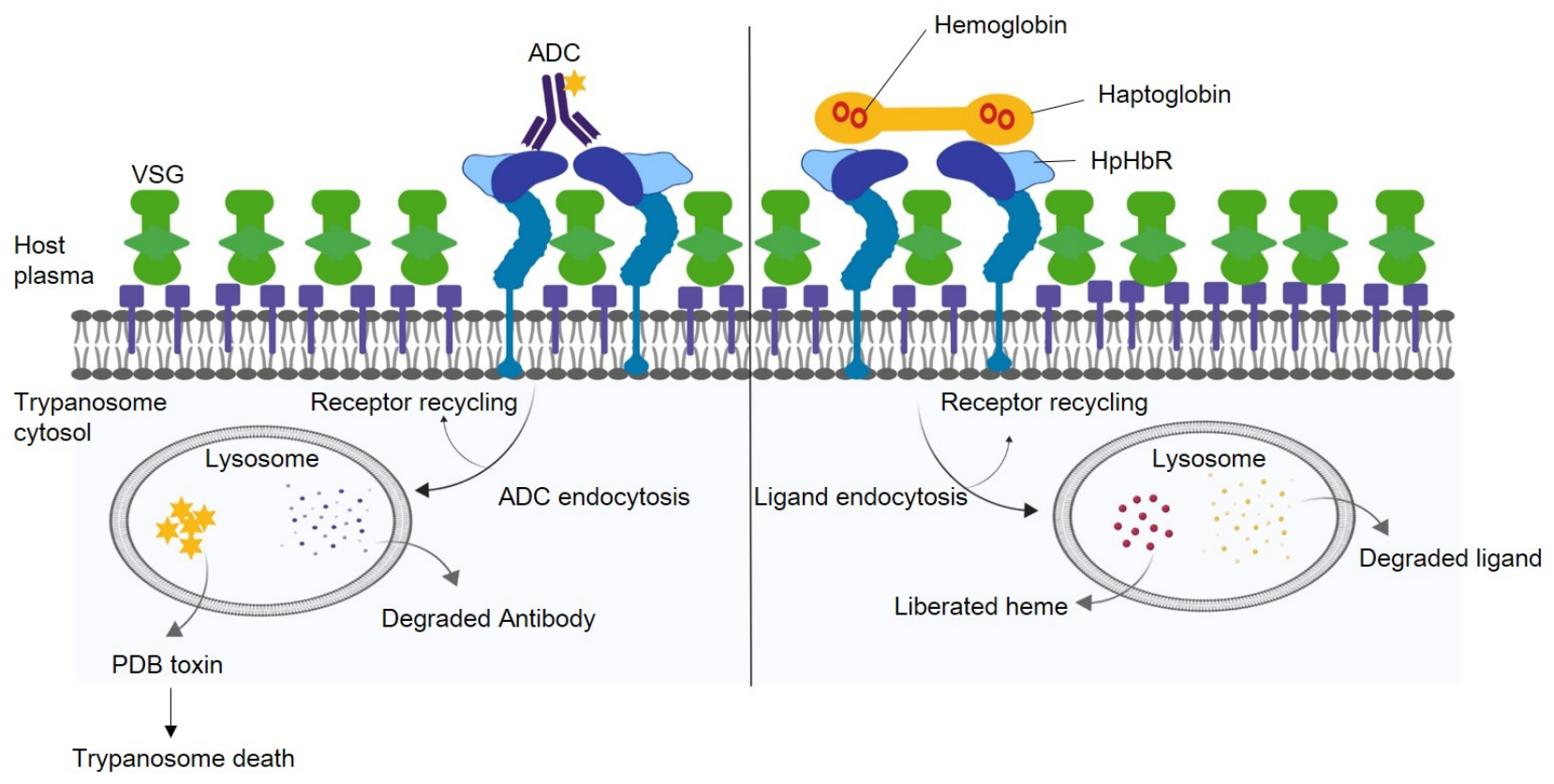

Figure 3

1008 Schematic representation of the mechanism of action of how an antibody drug conjugate (ADC) 1009 targeting a Trypanosoma brucei parasite. LEFT: Upon binding to the haptoglobin-haemoglobin receptor $(\mathrm{HpHbR})$ on the surface of the parasite, the ADC is internalized, whereby the pyrrolobenzodiazepine (PBD) toxin payload is liberated to exert it toxic action, ultimately leading to death of the parasite. RIGHT: The normal function of the HpHbR is to initiate internalization of the 1013 haptoglobin-hemoglobin complex for scavenging of heme from the environment, which is further 1014 utilized for generation of intracellular hemoproteins. 


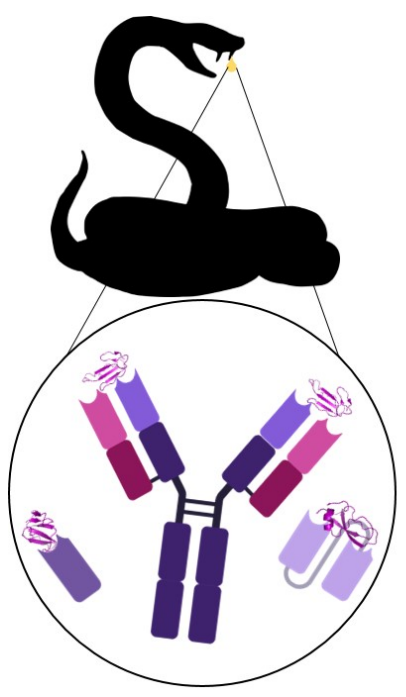

A

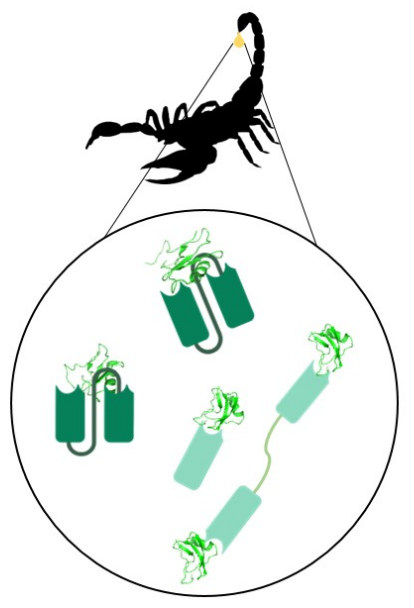

B

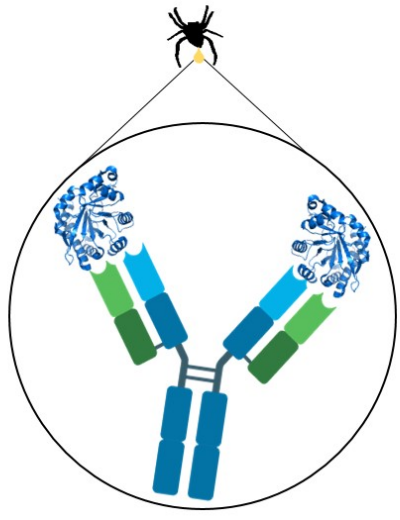

C

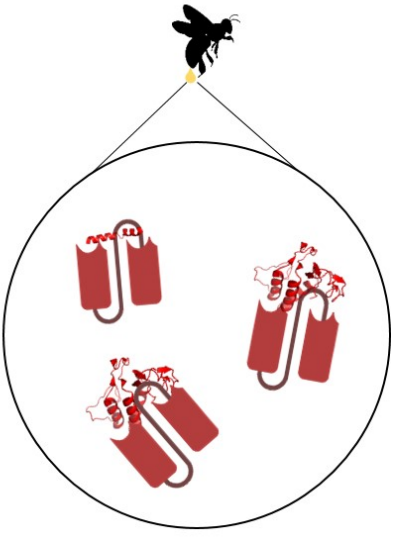

D

Figure 4

1018 Conceptual and schematic representation of selected monoclonal antibody formats that have been 1019 discovered against toxins from venomous animals. A) Human $\mathrm{IgG}, \mathrm{scFv}$, and $\mathrm{V}_{\mathrm{H}} \mathrm{H}$ antibodies are 1020 shown binding to selected snake toxins (cytotoxin-1 (5NQ4), dendrotoxin 1 (1DEM), and alpha1021 cobratoxin $(2 \mathrm{CTX})$ ). B) $\mathrm{scFv}, \mathrm{V}_{\mathrm{H}} \mathrm{H}$, and divalent $\mathrm{V}_{\mathrm{H}} \mathrm{H}$ construct antibodies are shown binding to 1022 selected scorpion toxins (AahII (1PTX), Cn2 (1CN2), and Css2 (2LI7)). C) Murine IgG antibodies 1023 are shown binding to a selected spider toxin (phospholipase D, (4Q6X)). D) scFv antibodies are 1024 shown binding to selected bee toxins (mellitin (2MLT) and bee venom phospholipase $\mathrm{A}_{2}$ (1POC)). PDB IDs were obtained from the Protein Data Bank (https://www.rcsb.org). 